\title{
EXPERIMENTAL ANALYSIS OF THE FEASIBILITY OF POLYDISPERSE DROPLET WATER FLOW USING AT FIRE EXTINGUISHING
}

\author{
Ivan S. Voitkov ${ }^{1}$, Maxim V. Zabelin ${ }^{1}$, Alena O. Zhdanova ${ }^{1, \text { a }}$ \\ ${ }^{1}$ National Research Tomsk Polytechnic University, 634050 Tomsk, Russian
}

\begin{abstract}
With use of modern diagnostic methods the experimental researches of the process of the sprayed water evaporation at its movement through a flame of the fixed height was conducted. The change ranges of the main integrated evaporation characteristics of the sprayed water droplets (rates, sizes, concentration in a flow) are established. It is shown that at the extinguishing of fires the most expedient decision is the use of polydisperse droplet flows.
\end{abstract}

\section{Introduction}

Specialized sprayer unit, generating liquid flows, particularly, sprinkler and deluge sprayers, is an integral part of majority modern firefighting systems. However, the effectiveness of such systems is not high. This problem is due to the fact that the final result of extinguishing as a rule is filling in of burning surface by extinguishing composition to the extinction of the flame. Such approach along with fire responses leads to such after growth, as the considerable excess expenditure of extinguishing composition and, as a result, having filled in with its rooms. It isn't so harmless, as may seem. The damage from an excessive flood of buildings and rooms often causes the losses comparable, and sometimes much exceeding caused by a fire. Besides, the mentioned sprayers are applied generally in systems of high pressure that creates the difficulties connected with the necessity of the appliance of the additional delivery equipment.

As an alternative to described perspective technologies of water mist using at fire of varying degrees of complexity extinguishing has been widely discussed recently [1,2]. Currently water mist sprayers are actively produced. Results of researches [35] which show that the sprayed phlegmatizators of burning can localize rather effectively a flame (and to liquidate the ignition center as a whole) are published. Thus, one of the main tasks which faces to the scientists by the development of such technology is the achievement of conditions of full extinguishing liquid evaporation in a flame zone. This effect is the determinant mechanism in fight of water mist against fire (intensive evaporation of liquid in a fire area promotes the considerable lowering of a flame temperature). As a means of intensification of liquid evaporates, as a rule offers the approaches consisting in a change of its initial temperature [4] and its delivery speed in the fire zone [5], addition in liquid before feed of different admixtures and inclusions [6]. However, the paramount factor exerting a determinant influence on the degree of water droplet evaporation in the flame zone are undoubtedly being the initial size of droplets in the flow. The purpose of this work is the experimental analysis of the feasibility of polydisperse water droplet flow using at fire extinguishing with using of the modern optical diagnostic techniques of gas-vapordroplet flows.

\section{Experimental setup and procedure}

The experimental setup (Fig. 1) was used in carrying out of experimental researches. On basic elements the setup is similar to applied in $[4,5]$ and includes the modern cross-correlation registration equipment, working at the base of non-contact optical methods of "tracer" visualization such as "Particle Image Velocimetry" (PIV) and "Interferometric Particle Imaging" (IPI) [7, 8].

The technique of carrying out experiments included the following procedures. The kerosene $(250 \mathrm{ml})$ was filled with interwalled space of cylinder 14 . After that, it was placed at the base of the heat-resistant translucent cylindrical channel 13 . The ignition of kerosene started before the experimentation. The internal space of channel 13 was filled by high temperature combustion products generated during the burning of kerosene. After setting time ( 280 seconds), necessary for heat-up of inner cylinder cavity 13 up to the average temperatures of a typical fire $(1070 \pm 30 \mathrm{~K})$, water from vessel 7 through the channel 8 was pumped on an entrance of the atomizer 9. Then input of liquid droplets to the channel 13 filled with high-temperature combustion products were

\footnotetext{
${ }^{\text {a }}$ Corresponding author: zhdanovaao@tpu.ru
} 


\section{EPJ Web of Conferences}

carried out. By means of light "pulse" 6 a trajectory of droplet movement was illuminated. Procedure of video registration of droplets was carried out by a cross-correlation digital camera 3. For contrast increase of videograms which were received with crosscorrelation digital camera the titanium dioxide (relative mass concentration (quantas) is $0.5 \%$ ) was added to an experimental liquid before the experimentation. The $\mathrm{TiO}_{2}$ nanopowder acted as a "tracers". Video images were transferred to the personal computer (PC) 4. Then, according to techniques [8,9], the instant distributions of rates and the sizes of the sprayed liquid droplets on an entrance and an exit from the channel 13 were defined.

Temperature of combustion products in the channel 13 was controlled by chromel-alumel thermocouples (range of taken temperatures $-273-1373 \mathrm{~K}$, a tolerance $\Delta=3.3 \mathrm{~K})$ at levels different in height $(0.15 \mathrm{~m}, 0.5 \mathrm{~m}, 0.85 \mathrm{~m})$ and made $1070 \pm 30 \mathrm{~K}$. The technique of thermocouple measurements was used. Systematic errors of gas temperature measurement didn't exceed $2.5 \%$.

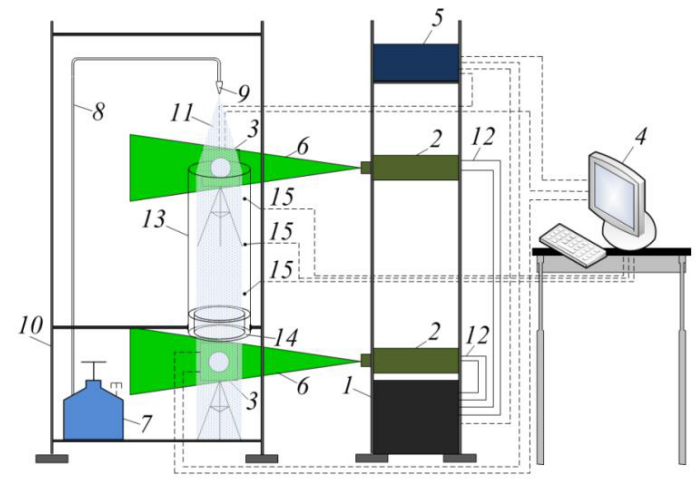

Figure 1. A scheme of experimental setup: 1 - laser emission generator; 2 - double pulsed solid-state laser; 3 - cross-correlation digital camera; 4 - PC: personal computer; 5 - synchronizer; 6 - light "pulse"; 7 - vessel with experimental liquid; 8 - channel of experimental liquid supply; 9 - atomizer (dosing device); 10 - tripod; 11 - experimental liquid droplets; 12 - cooling liquid channel of laser; 13 - heat-resistant cylinder; 14 hollow cylinder; 15 - thermocouples.

\section{Results and discussion}

The polydisperse droplet flow of sprayed water with initial sizes of drops in it $0.01<R_{\mathrm{m}}<0.4 \mathrm{~mm}$ was generated during experimentations. Dispersed of droplets in the flow meets the standards of [9]. According to this standard the water flow can be considered mist if $99 \%$ of droplets of all water volumes have the size less than $1000 \mathrm{~mm}$. At calculation of integrated characteristics of the evaporation process of water all droplets were divided according to the sizes into several groups: $1-0.01 \leq R_{\mathrm{m}} \leq 0.09 \mathrm{~mm}, 2-$ $0.09<R_{\mathrm{m}} \leq 0.16 \mathrm{~mm}, 3-0.16<R_{\mathrm{m}} \leq 0.23 \mathrm{~mm}, 4-0.23<R_{\mathrm{m}} \leq 0.3 \mathrm{~mm}, 5-0.3<R_{\mathrm{m}} \leq 0.4 \mathrm{~mm}$. Parameter $\Delta R$, which characterizes the decrease of the average conditional radius of the droplets group of movement through the high - temperature area was entered into consideration. $\Delta R=\left(\left(R_{\mathrm{m}}{ }^{\text {inp }}-R_{\mathrm{m}}{ }^{\text {out }}\right) / R_{\mathrm{m}}{ }^{\text {inp }}\right) \cdot 100, \%$, where $R_{\mathrm{m}}$ inp,$R_{\mathrm{m}}^{\text {out }}$ - average radius of the droplets group at the inlet and outlet of the channel $13, \mathrm{~mm}$.

Figure 2 shows typical videograms of water mist and the instantaneous velocity fields at the inlet and outlet of the hightemperature gas area. Essential change of concentration $\alpha_{\mathrm{m}}$ of considered droplets groups in comparison to initial values (table) is established. Thus, the concentration $\alpha_{\mathrm{m}}$ for droplets of groups 3-5 at the outlet of the channel with combustion products is close to 1 , for groups 1,2 it is respectively that $\alpha_{\mathrm{m}}=0$. At the entrance to the channel the concentration $\alpha_{\mathrm{m}}$ of droplets for groups 1,2 is slightly less than 0.45 (Table). It can be concluded that essential change of the sprayed liquid dispersion (as a result, composition of gas-vapor-droplet mix) takes place at its movement through the high-temperature area. 


\section{Thermophysical Basis of Energy Technologies 2015}

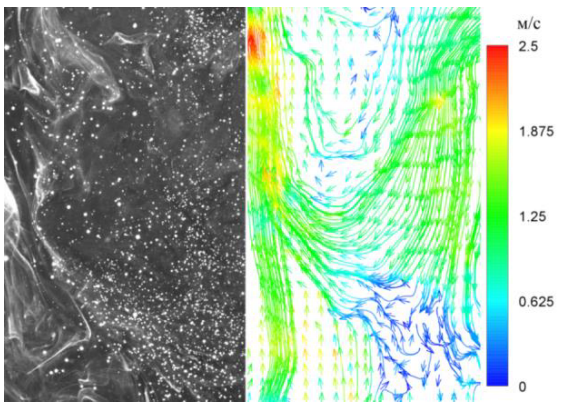

$a$
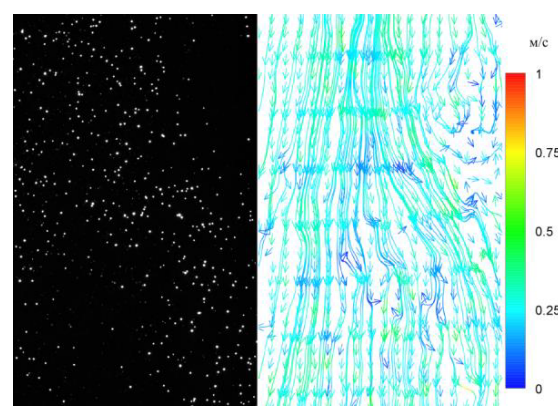

$b$

Figure 2. Videograms of the liquid droplets group and the velocity field of "tracer" particles at the input $(a)$ and output $(b)$ of the hightemperature gas area at $U_{\mathrm{m}}=1.5 \mathrm{~m} / \mathrm{s}$.

Table 1. Values of the main integrated evaporation characteristics of water droplets moving through a flame.

\begin{tabular}{|c|c|c|c|c|}
\hline Parameter name & Group number & At the channel inlet & \multicolumn{2}{|c|}{$\begin{array}{c}\text { At the channel } \\
\text { outlet }\end{array}$} \\
\hline$T_{\mathrm{w}}, \mathrm{K}$ & - & - & 293 & 303 \\
\hline$U_{\mathrm{m}}, \mathrm{m} / \mathrm{s}$ & - & 0.95 & 0.48 & 0.36 \\
\hline \multirow{5}{*}{$R_{\mathrm{m}}, \mathrm{mm}$} & 1 & 0.078 & - & - \\
\cline { 2 - 5 } & 2 & 0.139 & 0.071 & - \\
\cline { 2 - 5 } & 3 & 0.205 & 0.135 & 0.074 \\
\cline { 2 - 5 } & 4 & 0.272 & 0.197 & 0.128 \\
\hline \multirow{5}{*}{$\alpha_{\mathrm{m}}$} & 5 & 0.333 & 0.251 & 0.182 \\
\cline { 2 - 5 } & 1 & 0.063 & - & - \\
\cline { 2 - 5 } & 2 & 0.381 & 0.134 & - \\
\cline { 2 - 5 } & 3 & 0.323 & 0.297 & 0.119 \\
\cline { 2 - 5 } & 4 & 0.188 & 0.424 & 0.439 \\
\hline
\end{tabular}

It is also established (Table) that, for example, at an initial flow rate of $U_{\mathrm{m}}=0.95 \mathrm{~m} / \mathrm{s}$ and temperature of $T_{\mathrm{w}}=303 \mathrm{~K}$ the droplets of group 5 evaporate for about $45 \%$, group $4-53 \%$, group $3-64 \%$. Droplets of 1 and 2 groups evaporate completely. Thus, to extinguish fires in rooms (provided that the flame height does not exceed 1-2 $\mathrm{m}$ and the temperature of the quenching liquid in the firefighting system corresponds to the room temperature), use of droplets with $R_{\mathrm{m}} \leq 0.23 \mathrm{~mm}$ is represented to the most expedient. However, such approach, most likely, won't bring success in practice because quite essential part (about 50\%) of droplets with sizes less than $0.16 \mathrm{~mm}$ is subject to a turn and the subsequent ablation by a stream of ascending combustion products (Fig. 2, $a$ ). Rather large liquid droplets $\left(R_{\mathrm{m}}>0.23 \mathrm{~mm}\right)$, unlike small, practically in full enter to flame area, but because of low evaporation completeness (less than 53\%), they aren't capable to play a crucial role in a flame temperature decrease due to phase transformations.

Thus, using of a polydisperse droplets flow at ignitions extinguishing is represented as the most rational decision. Large droplets $\left(R_{\mathrm{m}}>0.23 \mathrm{~mm}\right)$ without special difficulties enter into the combustion zone. They reduce the draft developed by a fire, and provide further penetration into a combustion zone of smaller droplets. Besides, large droplets are capable to pass completely a flame (Fig. $2 \mathrm{~b}$ ) and to irrigate burning surfaces and the surfaces not yet mentioned by a fire. Cooling of these surfaces prevents further spread of flame. Droplets with $0.09<R_{\mathrm{m}} \leq 0.23 \mathrm{~mm}$, forming the majority part of flow (at least $50 \%$ ), at moving through a flame evaporates almost in full (Table). Therefore, they promote to a gradual decrease in fire temperature lower than temperatures of the thermal decomposition beginning of burning designs and materials. The smallest liquid droplets $\left(R_{\mathrm{m}} \leq 0.09 \mathrm{~mm}\right)$, absorbing soot particles, provided their sedimentation in the air. The gas-vapor-droplet mix formed as a result of these processes is capable to force out gradually an oxidizer from a fire zone.

\section{Conclusion}

To use of optical diagnostic methods of gas-vapor-liquid flows (PIV and IPI) the change ranges of the main integrated evaporation characteristics (the sizes, rates, concentration) of the sprayed water droplets are determined at movement in the conditions corresponding to real fires. It is established that for the most effective expenditure of water, use of polydisperse droplet streams with size droplets of $0.01 \leq R_{\mathrm{m}} \leq 0.4 \mathrm{~mm}$ is advisable. For achievement of the best effect it is possible to recommend layer-by-layer dis- 
persion of liquid, or its pulverizing when the sizes of droplets gradually increase from the flow center to its periphery (variable dispersion).

The reported study was partially supported by the Russian Science Foundation (No. 14-39-00003).

\section{References}

1. B. Yao, B.H. Cong, J. Qin, W.K. Chow, Fire Saf. J. 47, 32-39 (2012)

2. M. Guptaa, R. Rajoraa, S. Sahaia, R. Shankar, A. Ray, S.R. Kale, Fire Saf. J. 54, 130-142 (2012)

3. D.O. Glushkov, G.V. Kuznetsov, P.A. Strizhak, Math. Problems Eng. 2014, 920480, 8 (2014)

4. R.S. Volkov, G.V. Kuznetsov, P.A. Strizhak, J. Eng. Phys. Thermophys. 87, 2, 450-458 (2014)

5. R.S. Volkov, O.V. Vysokomornaya, G.V. Kuznetsov, P.A. Strizhak, J. Eng. Phys. Thermophys. 86, 6, 1413-1418 (2013)

6. CN 103041532 A. Multi-electron conductive material extinguishing agent.

7. R.D. Keane, R.J.Adrian, Appl. Sci. Res. 49, 191-215 (1992)

8. J. Westerweel, Meas. Sci. Technol. 8, 1379-1392 (1997)

9. NFPA 750: Standard on Water Mist Fire Protection Systems (USA, 2010) 